\title{
LAS TECNOLOGÍAS DE LA INFORMACIÓN Y DE LA COMUNICACIÓN Y SU USO POR LOS NIÑOS Y LOS ADOLESCENTES
}

\author{
CARMELO GARITAONANDIA \\ Profesor Del Departamento De Periodismo Universidad Del País Vasco \\ EMILIO FERNÁNDEZ \\ Profesor Del Departamento de Comunicación Audiovisual Universidad Autónoma De Barcelona \\ Jose Antonio Oleaga \\ Profesor Del Departamento De Sociología Universidad Del País Vasco
}

\begin{abstract}
Resumen
Este trabajo analiza los modos en que se relacionan los niños y los adolescentes con las diferentes tecnologías de la información y la comunicación (TIC), tecnologías que les permiten acceder a contenidos multimedia, con nuevas posibilidades interactivas, y a comunicarse entre sí. Los niños y los jóvenes han integrado perfectamente estas tecnologías en sus vidas y no se puede decir que su uso perjudique sus relaciones familiares y personales, dejando fuera de nuestro estudio los casos de adicción en el consumo y/o las conductas patológicas. Los niños y los jóvenes perciben sólo la versión lúdica de los aparatos que manejan con más asiduidad. Aunque el factor de diversión es importante también en los teléfonos móviles, en su uso prima el factor comunicativo, como lo demuestra el hecho de que los mensajes y las llamadas sean los aspectos más valorados. Los mayores encuentran también un uso escolar al ordenador y al acceso a Internet, para obtener información, pero incluso éstos usan los equipos informáticos para jugar o entretenerse (oír música, por ejemplo), o para comunicarse también, a través del e-mail y la mensajería instantánea. Este componente lúdico asociado a los equipamientos tecnológicos es el que permite que los niños y jóvenes vean estos aparatos como medios de comunicación en diferentes sentidos y es el intercambio de experiencias derivadas de su consumo lo que dota a estas tecnologías de su verdadero valor
\end{abstract}

\footnotetext{
* Este artículo se fundamenta en investigaciones actuales sobre el uso y consumo de los media por los niños y los jóvenes, si bien la investigación inicial en los diferentes países europeos fue la base de un proyecto internacional titulado "Children and the Changing Media Environment. A European Comparative Study", desarrollado de 1996 a 2001. Carmelo Garitaonandía fue responsable del grupo español. Dicho proyecto fue dirigido por las profesoras Sonia Livingstone y Moira Bovill, del Departamento de Media and Communications, de la London School of Economics, y financiado por la Broadcasting Standards Commission, por la dirección general de la UE the Youth for Europe Programme (EC-.DGXXII) y la Fundación Europea de la Ciencia (ESF). El informe final de nuestro trabajo fue publicado únicamente en inglés y su referencia completa aparece en las referencias bibliográficas. Una versión de este trabajo fue invitada a presentarse en las XVI Jornadas de Pediatría en Atención Primaria (Vitoria, 19-26 de Noviembre de 2004).
} 
Carmelo Garítaonandia Emilio Fernández Jose Antonio Oleaga,

\begin{abstract}
This paper analyses the relationship between children and teenagers and Information and Communication Technology (ICT), which permits them to have access to new multimedia contents and provides them with the opportunity for interactivity, and for communication with each other. This technology is perfectly integrated in the lives of children and teenagers, and has no adverse effects on either their family or social relationships. In this study we have not observed cases of addiction or pathological behaviour in respect of youngsters' use of ICT. Children and teenagers' basic attitude to ICT is fundamentally one of play and entertainment; although whilst they recognise the "fun" aspect of the mobile telephone, its principal use is for communication, as may be seen from the fact that they give the greatest value to the sending of messages and making and receiving calls. Older children also use the computer and the Internet for school work and to obtain information, but even so they continue to use this technology for play or entertainment (to listen to music, for example), and to communicate with each other by e-mail or the instant message system. It is the strong association between play and entertainment and ICT which leads children and teenagers to principally consider this technology as a means of communication, and it is the exchange of experiences based on this use which gives it its true value between Journalism and Literature. The aim is not to answer the questions just mentioned, but, with the help of these authors, point out some issues we regard as necessary when trying to answer them.
\end{abstract}

\title{
INTRODUCCIÓN
}

Los años cincuenta marcan el inicio de los estudios sobre la influencia de los medios de comunicación audiovisuales en la infancia. La investigación de la profesora Hilde Himmelweit (Himmelweit, Oppenheim y Vince, 1958) influyó de forma decisiva en la políticas educativas relacionadas con la televisión y la propia regulación del medio en una Europa, la de los años 50, con preeminencia del sistema público de televisión. Desde entonces el mundo de la comunicación y los estímulos y mensajes que reciben los jóvenes desde los diferentes canales de interacción multimedia (radio, televisión, la web, los móviles, las consolas de videojuegos) han hecho más complejo el ecosistema de la comunicación en que se desenvuelven.

¿Cómo ha afectado y afecta la expansión de los nuevos medios de comunicación a la organización del tiempo de ocio de los niños y jóvenes, detraen tiempo de otras actividades individuales o colectivas para dedicarlo a la interacción con las nuevas formas de ocio multimedia? En este sentido, los efectos sobre la lectura en los niños ha sido ampliamente tratado (Koolstra and Van der Voort, 1996 y 1997). Mientras que los niños holandeses ven la televisión 2,3 horas de media diaria, sólo dedican unos 8 minutos a la lectura como ocio, concluyendo que la televisión induce, por una parte, a una disminución del tiempo dedicado a la lectura, y por otra, influye decisivamente en la capacidad para concentrarse en la misma. No todo son incidencias supuestamente negativas, la combinación de las tareas escolares y la audiencia de medios (música, por ejemplo) han tenido una incidencia positiva en los casos de trabajos escolares con "papel y lápiz" (Beentjes, Ko- 
olstra \& Van der Voort, 1996). Por su parte, Giovanni Sartori (1998) desde una visión apocalíptica señala que la televisión con su cultura visual predominante impide la formación de ciudadanos maduros y críticos pues la "televisión produce imágenes y anula los conceptos y de este modo atrofia nuestra capacidad de abstracción y con ella toda nuestra capacidad de entender". (Sartori, 1998:47)

Tradicionalmente el consumo de la TV se ha asociado a un bajo nivel de participación de los telespectadores, un modo de comunicación asimétrico, sin casi ninguna posibilidad de interacción por parte del receptor. Sin embargo, los nuevos medios de comunicación parecen invitar a una mayor participación, no solo más activa, sino interactiva, gracias al ordenador/lnternet y la televisión digital. Esta hipótesis hace surgir nuevas cuestiones sobre las diversas formas de participación y sobre cómo utilizan los niños estos medios y las gratificaciones que obtienen de su uso. Algunas investigaciones demuestran que los juegos de ordenador ayudan a la mayoría de los niños a desarrollar destrezas en la resolución de problemas (Weber y Fazal, 1994) (si bien una tercera parte de los niños estudiados en dicha investigación se sienten agresivos después de jugar con el ordenador) y también les permite desarrollar mejor su creatividad (Sefton-Green and Buckingham, 1996).

El papel de los media como agente socializador, en relación, o quizá en conflicto también, con otros agentes de autoridad y socialización (padres, escuela y amistades) ha sido objeto de numerosas investigaciones. Meyrowitz (1984) dice que la socialización en el universo electrónico genera el niño adulto, debido a que, a través de los medios de comunicación, tiene acceso a contenidos que le están vedados por razón de edad, lo cual produce una pérdida prematura de la inocencia. Liebes (1991) muestra cómo las imágenes de la TV tienen, a veces, más fuerza que los valores transmitidos por los padres durante el proceso de socialización. Pero la incorporación de ordenadores/conexión a Internet, televisión y otros equipamientos en las escuelas puede proporcionar, también, una más armoniosa relación entre las autoridades tradicionales y las actividades domésticas de los niños.

¿Cuál es el papel de los sistemas de estratificación, clases sociales, educación..., en la creación de desigualdades en el acceso a los media, su conocimiento y uso? Mientras que el análisis de la audiencia enfatiza la heterogeneidad de ésta con respecto a factores socio-culturales (Moores, 1993; Morley, 1986; Silverstone et al, 1989 ), la corriente de la gap hypothesis muestra que los grupos privilegiados, pero también los más motivados obtienen más de los media. Como consecuencia, se crean mayores desigualdades en el conocimiento en vez de una homogeneización cultural de la audiencia. ¿QQué desniveles de información y competencia pueden estar implantándose debido a las diferencias en cuanto a recursos materiales, accesibilidad e interés y apoyo familiar?

La importancia del contexto familiar en la formación de pautas de relación con los media ha sido objeto de numerosos estudios durante muchos años (Bausinger, 1984; Goodman, 1983; Liebes, 1991; Livingstone, 1992; Silverstone, Morley, Dahlberg y Livingstone, 1989; Huston \& Wright, 
Carmelo Garítanandia Emilio Fernández Jose Antonio Oleaga.

1996) o el rol particular de las madres (Nikken, Van der Voort, \& Van Bochove, 1996; Orozco Gómez $G$, 1996). Más que analizar al niño durante su relación con los medios de comunicación, su toma de decisiones individual y la organización de su tiempo entre otras cuestiones, la investigación propuesta estudia al niño en el contexto familiar, con sus parámetros culturales y sociológicos. De esta forma, podemos preguntarnos sobre cuestiones relativas al rol de los padres, los medios electrónicos domésticos, la distribución espacial del hogar y las pautas de la dinámica familiar, como factores extramediáticos determinantes para poder entender la relación entre el niño y la TV y el resto de los contenidos multimedia con los que interactúa. O el de los maestros, cuya mediación sistemática podría intensificar las habilidades interpretativas de la televisión por parte de los niños (Tidhar, 1996).

Una revisión realizada por Comstock y Paik (1991) indica que la relación de los niños con la televisión está siendo determinada por su disponibilidad de tiempo libre, una aproximación no selectiva en su programa elegido y una escasa implicación con lo que ven. Estas pautas pueden cambiar en la medida en que las telecomunicaciones y otros dispositivos multimedia (canales musicales, juegos de ordenador, consolas) están cada vez más dirigidos a los niños y a los jóvenes como nuevos consumidores con poder adquisitivo y que prefieren tener su propio equipamiento antes que compartir el familiar (Sherman, 1996).

Una buena parte de las investigaciones se preocupan de los efectos que los mass-media producen en los niños (Comstock y Paik, 1991). Pero sólo unos pocos se preguntan por qué ven la televisión y qué les gusta de ella. Del mismo modo, es cada vez mayor la literatura sobre las audiencias de los nuevos media electrónicos y apenas una pequeña parte de ésta se centra en el estudio de la audiencia infantil y adolescente, si bien los adolescentes son consumidores privilegiados de videojuegos y juegos de ordenador. Por una parte, los juegos que prefieren son habitualmente los violentos (Funk and Buchman, 1996), y por otra, estos juegos en general pueden crear en una pequeña minoría patologías adictivas (Fischer, 1994).

La violencia y el sexo en la programación infantil de televisión ha sido y es una constante preocupación en la atención de investigadores, educadores y en las administraciones de todo el mundo y en particular en los Estados Unidos (Dubow and Miller, 1996; Kubey, 1996; Wartella, 1996) como lo refleja la aprobación de The children's Television Act of 1990 (Knell, 1995), si bien ha tenido sólo una pequeña incidencia positiva en la televisión infantil (Hayes, 1994). Sirva, también, como muestra de esta preocupación la implantación del V-chip en los televisores para el control de la programación violenta, pornográfica o soez que puede estar al alcance de los niños, a partir de la Telecommunications Competition and deregulation Act, aprobada por el Congreso norteamericano en 1996 (Potten \& Warren, 1996; Makris, 1996).

En Europa la sensibilidad social y política sobre las relaciones entre la televisión y niños es elevada y organismos como el British Standards Commission y el Conseil Superieur de l'Audiovisuel en Francia realizan una importante labor en este terreno. El Parlamento español aprobó la Directiva del Consejo de Europa, la llamada "Televisión sin fronteras, (1989) y su modificación de 
1997, introduciéndolas en la legislación nacional. Estas directivas contienen en su articulado una normativa dirigida a la protección del menor y sobre la programación destinada al público infantil, para que las instituciones velen porque los contenidos de los programas en sus respectivos países no vayan en contra del desarrollo mental, físico o moral de los niños.

Por otra parte, casi todas las leyes españolas concernientes a los derechos de emisión como la ley de creación del Ente de RTVE, la Ley de Terceros Canales, o las Leyes de creación de las Televisiones de las Comunidades Autónomas que poseen canales propios de televisión, tienen artículos similares a los mencionados. Pero hay una importante laguna en la ley de televisiones privadas, donde no se hace referencia a la protección de los niños y jóvenes. Por ello, el 26 de marzo de 1993, el Ministerio de Educación y Ciencia firmó un acuerdo de autorregulación de programas para niños y jóvenes, a modo de código ético, con TVE, Antena 3 TV, Tele 5 y Canal +, que tampoco ha tenido mejores resultados. Por su parte, el 20 de diciembre de 1993 se constituyó la Comisión Especial Sobre los Contenidos Televisivos del Senado. Esta comisión ha realizado una exhaustiva evaluación del estado de los contenidos televisivos a través de las comparecencias de personas pertenecientes a los más diversos ámbitos de la sociedad adoptando una serie de orientaciones sobre la televisión para la infancia y la juventud, y la creación de un Consejo Superior del Audiovisual, medida que fue aprobada unánimente. Ante los casi nulos resultados de estas medidas, el 9 de diciembre de 2004 el gobierno español firmó con los operadores de televisión de ámbito estatal Antena 3, Telecinco, Sogecable y TVE el Código de autorregulación sobre contenidos televisivos e infancia. Esta revisión del código anterior establece dos tramos horarios de especial protección de menores (entre las 8.00 y las 9.00 y entre las 17.00 y las 20.00 ) en los que estarán vetadas imágenes de sexo o violencia. Los fines de semana la franja matinal se extiende hasa las 12. El acuerdo sigue manteniendo la franja de protección general y que prohibe la emisión de contenidos inadecuados para la infancia entre las 6:00 y las 22:00 horas.

\section{USO Y CONSUMO DE LOS MEDIA POR NIÑOS Y JÓVENES}

El nivel de equipamiento de los hogares españoles en televisores, video, reproductores de DVD, cámaras digitales, gameboys y consolas de video juegos, y del que disfrutan nuestros hijos, incluido el teléfono móvil, es elevado y muy similar al del resto de los países de la Unión Europea. Sin embargo, los hogares españoles están por debajo de la media en el número de ordenadores en el hogar y en la conexión a Internet. Prácticamente todos los niños y jóvenes, de cualquier edad, tienen un aparato de televisión en color en su casa, casi el $60 \%$ de los hogares disponen de dos o más televisores, y prácticamente todos los hogares con niños tienen un vídeo/dvd. Este nivel tecnológico hace que muchos niños y jóvenes tengan su propio equipamiento en la habitación, incluida a veces la conexión a Internet, lo que hace que los controles parentales, por ejemplo, del uso en tiempo y contenidos de la televisión o su navegación en la red, sean mucho menores a los que se producían anteriormente. Esta tendencia a que se genere una autonomía de consumo en sus habitaciones es lo que en el mundo anglosajón se conoce como bedroom culture (cultura de la habitación). En las fechas en que realizamos el trabajo de campo de nuestro estudio, el $63 \%$ de 
Carmelo Garítanandia Emilio Fernández Jose Antonio Oleaga,

los niños ingleses y el $60 \%$ de los niños daneses tenían su propio receptor de televisión en la habitación. En la encuesta realizada en el Reino Unido en el 2004 y publicada con el título, UK children go on-line, se añade que la quinta parte de los niños (19\%) tienen acceso a Internet en sus propias habitaciones: $22 \%$ de chicos frente al $15 \%$ de chicas, $21 \%$ de clase media frente a $16 \%$ de clase trabajadora, $10 \%$ de 9 a 11 años frente a $26 \%$ de 16 a 17 años.

Tabla 1. Evolución del equipamiento de los hogares españoles (\% de hogares)

\begin{tabular}{|l|c|c|c|c|}
\hline & 1988 & 1993 & 1998 & 2003 \\
\hline TELEVISIÓN & 98.2 & 99.0 & 99.5 & 99.6 \\
\hline una & 76.5 & 52.3 & 40.3 & 39.7 \\
\hline dos o más & 21.6 & 46.8 & 59.2 & 59.8 \\
\hline con dvd conectado & - & - & - & 24.4 \\
\hline ANTENA PARABÓLICA & 0.4 & 2.6 & 9.0 & 14.3 \\
\hline VIDEO & 25.9 & 54.5 & 69.2 & 70.7 \\
\hline TV DE PAGO, \% ABONADOS & - & - & - & 20.1 \\
\hline CABLE & 4.4 & 2.9 & 3.9 & 7.5 \\
\hline CÁMARA DE VIDEO & 0.6 & 6.2 & 12.8 & 17.4 \\
\hline ORDENADOR PERSONAL & & & & \\
\hline con cd-rom & - & - & 16.9 & 35.7 \\
\hline con dvd & - & - & - & 16.4 \\
\hline con modem & - & - & 6.0 & 25.6 \\
\hline portátil & - & - & - & 3.7 \\
\hline VIDEO CONSOLA & - & - & 18.5 & 18.0 \\
\hline RADIO & 88.9 & 96.0 & 96.9 & 96.0 \\
\hline SOLO RADIO & - & 69.1 & 68.2 & 66.6 \\
\hline RADIO CASSETTE & - & 69.9 & 67.1 & 54.5 \\
\hline CADENA HI-FI & 15.2 & 40.2 & 58.9 & 61.3 \\
\hline TELEFONO & 64.3 & 80.6 & 89.8 & 97.1 \\
\hline fijo & - & - & - & \\
\hline móvil & - & - & 74.3 & \\
\hline
\end{tabular}

Fuente: Informe del Estudio General de Medios 2004. Puede consultarse en http://www.aimc.es

El uso de los equipamientos tecnológicos en el hogar se circunscribe básicamente para el entretenimiento y el juego. El único equipo que además de una función lúdica tiene un uso escolar es el ordenador. Para algunos adolescentes el ordenador se convierte en una herramienta importante de estudio: escritura y presentación de trabajos, búsqueda de documentación (sobre todo en Internet y/o consulta de enciclopedias en $\mathrm{cd}$ ) y aprendizaje de inglés. La televisión y el vídeo sólo tienen uso educativo en algún caso absolutamente excepcional (por ejemplo: vídeos del National Geographic). 
La televisión continúa dominando el ocio de los niños europeos: en todos los países es el medio más usado, sobre el que más se habla con la familia y amigos, y el que se elige con más frecuencia para el entretenimiento.

Los niños y jóvenes españoles ven la televisión casi todos los días de la semana y le dedican algo más de dos horas y cuarenta minutos. De ellos algo más de media hora se debe al consumo medio de vídeo/dvd al día, con una frecuencia de algo más de 2 días a la semana. Los niños de 4 a 12 años son el grupo de edad-seguido de los jóvenes y adultos jóvenes de 13 a 24 años que menos tiempo pasa frente al televisor, frente a más de tres horas y tres cuartos que consumen el resto de los españoles. La diferencia más notable se da con los mayores de 64 años (obviamente los que más tiempo tienen por estar jubilados) que dedican cinco horas de media, el doble que los niños. Aunque los controles de audiencia a través de audímetros (Nielsen-Sofres) se realizan a partir de los 4 años, y sabemos que a esa edad ya un $91.2 \%$ ve la televisión, antes, a partir de los 2 años, el $55 \%$ de los niños españoles ve la televisión de acuerdo con las respuestas que dan sus padres en las encuestas sociológicas.

Tabla 2. Tiempo empleado por los niños europeos en cada medio, por género y edad (minutos por día)

\begin{tabular}{|l|l|l|l|l|l|}
\hline MEDIIA & chicos & chicas & $9-10$ años & $12-13$ años & $15-16$ años \\
\hline Televisión & 134 & 130 & 118 & 137 & 136 \\
\hline Audio media (música...) & 73 & 98 & 48 & 78 & 120 \\
\hline Juegos (PC, consola,...) & 47 & 14 & 29 & 34 & 27 \\
\hline Video/DVD & 33 & 25 & 30 & 30 & 27 \\
\hline Libros & 15 & 28 & 25 & 24 & 16 \\
\hline PC (no para juegos) & 23 & 11 & 11 & 17 & 21 \\
\hline Comics & 13 & 7 & 14 & 12 & 6 \\
\hline Revistas & 9 & 11 & 6 & 11 & 11 \\
\hline Periódicos & 9 & 7 & 3 & 7 & 11 \\
\hline TOTAL & $\mathbf{3 5 6}$ & $\mathbf{3 3 1}$ & $\mathbf{2 8 4}$ & $\mathbf{3 5 0}$ & $\mathbf{3 7 5}$ \\
\hline
\end{tabular}

Fuente: Nuestra propia encuesta europea citada en "Children and Their Changing Media Environment. A European Comparative Study". Lawrence Erlbaum Associates, Mahwah (New Jersey) y London, 2001.

En los últimos años, salvo en Gran Bretaña y los países escandinavos, se ha dado una tendencia a reducir sensiblemente la programación infantil, quedando arrinconada a algunas horas en torno al desayuno y a las mañanas de los sábados y domingos. La razón básica ha sido que las televisiones públicas, pero sobre todo privadas, han acentuado el peso "generalista" de su programación y han entendido que los niños de 4 a 12 años son el grupo de población menos relevante, representan sólo $10.1 \%$ de la población española, y entre un 6-7,5\% de la audiencia media de la televisión dependiendo de la temporada. Además no tienen un importante poder adquisitivo directo, aunque sí por inducción de sus mayores. 
Carmelo Garítanandia Emilio Fernández Jose Antonio Oleaga,

Existen importantes diferencias en sus gustos televisivos marcadas por la edad y el sexo. A los más pequeños (6 y 7 años) les gustan abrumadoramente los dibujos animados, en especial a los niños $(66 \%)$, y a las niñas también los shows familiares (29\%). Los jóvenes adolescentes, chicos y chicas, se decantan sobre todo por las teleseries y los shows familiares, aunque ya hay algunas importantes diferencias. Para los chicos adolescentes el contenido favorito es el deporte $(30 \%)$, mientras que ellas prefieren las series $(37 \%)$.

Tabla 3. Programas de TV preferidos por los niños europeos de acuerdo con la edad

\begin{tabular}{|l|l|l|l|l|}
\hline & 6-7 años & $9-10$ años & $12-13$ años & $15-16$ años \\
\hline CHICOS & dibujos animados (63\%) & dibujos animados (23\%) & series (22\%) & deporte (22\%) \\
\hline & series (8\%) & series (20\%) & deporte (15\%) & comedias (16\%) \\
\hline & magazines (7) & deporte (15\%) & comedias (15) & series (16) \\
\hline CHICAS & dibujos animados (48\%) & culebrones (29\%) & culebrones (35\%) & series (33\%) \\
\hline & series (11\%) & series (25\%) & series (30\%) & culebrones (28\%) \\
\hline & culebrones (10) & dibujos animados (13) & comedias (13\%) & comedias (14\%) \\
\hline
\end{tabular}

Fuente: Nuestra propia encuesta europea citada en Children and Their Changing Media Environment. A European Comparative Study. Lawrence Erlbaum Associates, Mahwah (New Jersey) y London, 2001.

En cualquier caso, conviene destacar que los niños y los adolescentes prefieren abrumadoramente la programación de adultos (75\%) frente a la programación infantil-juvenil (25\%). Esta tendencia obviamente se acentúa con la edad, y ya en los adolescentes de 15 y 16 años su gusto por la programación de adultos se eleva al $92 \%$. Existe una diferencia notable por razones de sexo, ya que en las niñas las preferencias por los programas de adultos son elevadas incluso a la edad de 6 y 7 años (50\% las niñas respecto al $27 \%$ los niños), y así se mantienen siempre por encima hasta los de mayor edad, aunque las diferencias son muy pequeñas a edades superiores.

Tabla 4. Perfil del programa favorito de niños y jóvenes europeos por país, género y edad

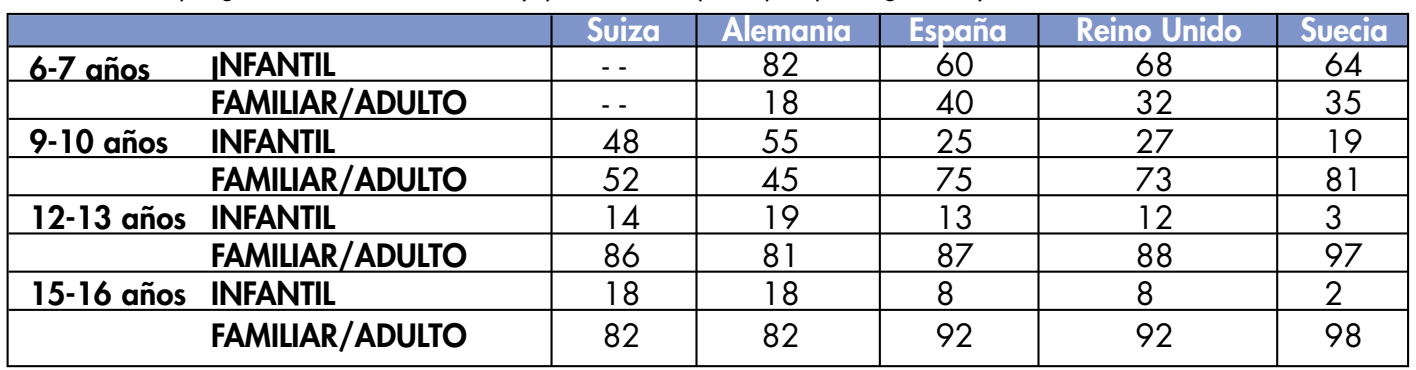

Fuente: Nuestra propia encuesta europea citada en Children and Their Changing Media Environment. A European Comparative Study. Lawrence Erlbaum Associates, Mahwah [New Jersey] y London, 2001 
Aunque este trabajo no pretende ser una promoción de la televisión digital de pago, es necesario constatar cómo la programación favorita de los niños que ven la televisión generalista es la programación de adultos progresivamente (40\% para niños de 6-7 años; $75 \%$ para 9 y 10 años; $87 \%$ para 12 y 13). Por su parte, los niños (entre 4 y 12 años) que tienen contratado Digital+ ven principalmente canales diseñados para el público infantil. Por orden de preferencia los canales más vistos por los niños de esta franja de edad son: Cartoon Network, Fox Kids, Nickelodeon, Disney Channel, FDF, Disney Ch+1, FOX, Toon Disney, Eurosport y C+ Deporte 1 (Nielsen Sofres, Julio 2004).

Ver la televisión y el vídeo o DVD es sobre todo un acto social, y lo normal es que nuestros hijos vean su programa favorito de televisión en compañía de la madre (39\%), el padre (28\%), la hermana/s $(24 \%)$, el hermano/s $(30 \%)$ o un amigo o amiga/s $(9 \%)$. Sólo una pequeña minoría (16\%) ven contenidos de televisivos o de vídeo solos.

\section{CONTROL Y REGLAS DE LOS PADRES PARA EL USO DE LA TELEVISIÓN.}

La violencia y el sexo en la programación infantil de televisión ha sido y es una constante preocupación de los padres, los educadores y de las administraciones de todo el mundo. Esta preocupación ha llevado en Estados Unidos a la implantación del violence-chip en los televisores fabricados a partir del 1 de Enero de 2000. El citado chip permite el control por parte de los padres del diálogo sugestivo, el lenguaje vulgar, las situaciones sexuales y la violencia (www.tvguidelines.org).

El Parlamento español aprobó la Directiva del Consejo de Europa, llamada de "Televisión sin fronteras" en 1989 y su modificación de 1997. Estas directivas contienen en su articulado una normativa dirigida a la protección del menor y hace hincapié también en la publicidad y la emisión de programación no destinada al público infantil.

En la familia, también las madres y los padres llevan a cabo una actividad reguladora sobre la gran cantidad de aparatos de acceso a contenidos multimedia que tienen sus hijos en el hogar, y tratan de influir en los consumos que de ellos hacen. No hay diferencias apreciables entre el control que ejerce la madre o el padre, aunque hay una ligera tendencia a que sea la madre la que controle más estas actividades. El control de los progenitores es mucho menor en lo que se refiere a la escucha de música, la lectura de libros o el uso del ordenador. Desde finales del pasado siglo se ha despertado por parte de muchos padres la necesidad de un control sobre la navegación a páginas de contenido sexual y chats a las que pueden tener acceso niños y jóvenes (http://www.internetsegura.net). A medida que los niños llegan a la adolescencia la observación de los padres sobre sus actividades disminuye, pero tampoco de una manera drástica. En esta edad decae mucho el control sobre los contenidos que ven en la televisión, pero, por ejemplo, la vigilancia sobre el uso del teléfono se acentúa hasta la adolescencia. 
En general parece que hay tres reglas sobre el uso de la televisión, prácticamente fijas en todos los hogares, que "los hijos aceptan y respetan".

- La primera es la hora de ir a la cama, que está marcada por razones de edad. La escala puede oscilar de las 9.45 de la noche para el niño de 6-7 años, cuando al día siguiente hay clase, hasta las 23.15 para el adolescente de 15-16 años.

$\Delta$ La segunda es el exceso de consumo de televisión.

- La tercera es la prohibición de programas violentos y los de sexo, de los que algún padre en las entrevistas personales llega a decir que son "verdadera pornografía". Sin embargo, la preocupación de los padres respecto al sexo explícito o al material pornográfico en los últimos años se ha desplazado de la televisión a Internet, aunque en realidad en la encuesta real de los jóvenes la importancia de la televisión y el vídeo se mantiene alta todavía.

Tabla 5. Preocupación de los padres británicos sobre el medio en que sus hijos (9-17 años) obtienen contenidos de sexo explícito o pornográfico (2004)

\begin{tabular}{|c|c|}
\hline porcentaje & medio \\
\hline $53 \%$ & Internet \\
\hline $20 \%$ & televisión \\
\hline $9 \%$ & vídeo/DVD \\
\hline $5 \%$ & revistas \\
\hline
\end{tabular}

Fuente: elaboración propia con datos de UK Children go on online

Tabla 6. Dónde han visto pornografía los jóvenes británicos (12-19 años) (2004)

\begin{tabular}{|c|c|}
\hline porcentaje & medio \\
\hline $68 \%$ & Internet \\
\hline $52 \%$ & Televisión \\
\hline $46 \%$ & Revistas \\
\hline $30 \%$ & Vídeo/DVD \\
\hline
\end{tabular}

Fuente: elaboración propia con datos de 'UK Children go on online'

Aunque no parece que haya una prohibición expresa, los padres no quieren que sus hijos vean determinados programas, como los "reality shows", por ejemplo. Por el contrario, les gusta que sus hijos vean documentales sobre naturaleza. En cualquier caso, madres y padres parecen defender la vía de la persuasión sobre la imposición, ya que con ésta última se suele conseguir menos. 
LAS TECNOLOGIAS DE LA INFORMACION ..

Carmelo Garítaonandia Emilio Fernández Jose Antonio Oleaga,

Tabla 7. Los programas más vistos en 2004 por los niños de 4 a 12 años

\begin{tabular}{|l|c|c|c|c|}
\hline & Cadena & N $^{\circ}$ de emisiones & Hora de inicio & Público infantil \\
\hline El Inquilino & A-3 & 3 & 21.56 & 497.000 \\
\hline Mis adorables vecinos & A-3 & 19 & 22.06 & 478.000 \\
\hline Manolito Gafotas & A-3 & 13 & 21.40 & 447.000 \\
\hline Los Simpson & A-3 & 364 & 14.11 & 437.000 \\
\hline Los Serrano & T-5 & 26 & 22.08 & 423.000 \\
\hline Ana y los 7 & TVE-1 & 22 & 22.05 & 409.000 \\
\hline
\end{tabular}

Fuente: GECA sobre datos de Nielsen-Sofres

\section{DE LAS ADICCIONES A LA RED Y LOS CONTENIDOS INADECUADOS PARA LOS NIÑOS}

La creación de la World Wide Wed a mediados de los años noventa ha dado lugar a la popularización de Internet y de sus diferentes aplicaciones: el correo electrónico, la navegación, los chats, los foros o los weblogs. Ello también ha llevado a muchos psicólogos a hablar de adicción a Internet (Chien, 2000), (Pratarelli \& Browne, 2002). Sin embargo, otros expertos relativizan el carácter adictivo del uso de la red. Así Helena Matute, catedrática de Psicología de la Universidad de Deusto, señala que Internet no produce adicción propiamente dicha sino ansiedad. La autora al referirse al cibersexo señala que Internet no provoca un índice de adicción superior al que existe en la sociedad y que la ansiedad inicial se atenúa en la mayoría de los casos en un plazo menor a un año (Matute, 2003).

Un estudio internacional realizado en 2004 sobre el uso de Internet en 14 países' por el UCLA World Internet project en el 2004, entre los que se incluye España, revela que los usuarios de Internet ven menos la televisión que los no conectados. Chile y Hungría son los dos países donde los internautas han reducido más su consumo de televisión. A causa de la red ven una media de cinco horas y 42 minutos menos de televisión a la semana. Por otra parte, en contra de otro de los mitos sobre Internet, este estudio constata que, en todos los países analizados, los internautas dedican más tiempo que los no usuarios a las actividades sociales.

Tabla 8. Evolución de la audiencia de Internet y de televisión en España

\begin{tabular}{|l|l|l|l|l|l|l|l|l|}
\hline & 1996 & 1997 & 1998 & 1999 & 2000 & 2001 & 2002 & 2003 \\
\hline Internet & 1,0 & 2,7 & 4,6 & 7,0 & 12,6 & 20,4 & 22,5 & 26,9 \\
\hline Televisión & 91,3 & 90,7 & 89,4 & 89,4 & 89,2 & 89,2 & 89,9 & 90,7 \\
\hline
\end{tabular}

Fuente: EGM, elaboración propia. Nota: para la audiencia de televisión es necesario haber visto la televisión algunos minutos el día anterior. 'Usuario de Internet' significa haber accedido a la Red al menos en los 30 últimos días.

\footnotetext{
'Gran Bretaña, Chile, China, Alemania, Hungría, Italia, Japón, Corea, Macao, Singapur, España, Suecia, Taiwán y Estados Unidos.
} 
La Europa de los 25 países arranca con 185 millones de internautas, situándose España ${ }^{2}$ entre la vieja Europa, cuyo porcentaje de usuarios es del $45.3 \%$, y los nuevos miembros, en los que la media sólo alcanza el $21.9 \%$. Según la primera oleada de encuestas de Estudio General de Medios del año 2004 (www.aimc.es) el $31.5 \%$ de los españoles mayores de 14 años están conectados a Internet, un nivel algo inferior, al de Irlanda, Bélgica, Italia, Francia, Estonia y Lituania, y muy inferior al de Suecia $(76.9 \%)$, Holanda $(66.0 \%)$, Dinamarca $(62.5 \%)$, Reino Unido (58.85) y Alemania $(54.3 \%)$. El incremento de 5.9 puntos respecto al año anterior demuestra el fuerte desarrollo que está teniendo el uso de la red, ya que es el incremento mayor de toda la historia. El uso que los jóvenes hacen de Internet (de 14 a 19 años) es del 69.14\%, sólo comparable a los adultos jóvenes (20 a 24 años) y muy superior a todos los bloques de edad, especialmente a partir de los 45 años. En el Reino Unido, por ejemplo, las tres cuartas partes de los niños de 9 a 19 años tienen acceso a Internet desde un ordenador de casa y el $92 \%$ desde la escuela. Su consumo mayoritario (67\%) es inferior a la hora diaria, lo que le hace distar todavía mucho del consumo televisivo.

Tabla 9. Porcentaje de usuarios de Internet en Europa. Mayo 2004

\begin{tabular}{|l|l|l|}
\hline & $\begin{array}{l}\text { población } \\
\text { en millones }\end{array}$ & $\begin{array}{l}\text { \% de } \\
\text { usuarios }\end{array}$ \\
\hline Alemania & 82.63 & $54.3 \%$ \\
\hline Francia & 59.69 & $37.3 \%$ \\
\hline España & 41.89 & $32.5 \%$ \\
\hline Estonia & 1.26 & $35.9 \%$ \\
\hline Holanda & 16.36 & $66.0 \%$ \\
\hline Italia & 56.15 & $35.4 \%$ \\
\hline Portugal & 10.38 & $19.2 \%$ \\
\hline Reino Unido & 59.15 & $58.8 \%$ \\
\hline Suecia & 8.99 & $76.9 \%$ \\
\hline
\end{tabular}

Fuente: diario El País

Tabla 10. Audiencia de Internet en España. Perfil por edad. Acumulado 2003

\begin{tabular}{|l|c|c|}
\hline & población & $\begin{array}{c}\text { Usuarios } \\
\text { úlimo mes }\end{array}$ \\
\hline 14 a 19 años & $8.2 \%$ & $18.0 \%$ \\
\hline 20 a 24 años & $9.0 \%$ & $18.2 \%$ \\
\hline 25 a 34 años & $19.4 \%$ & $29.9 \%$ \\
\hline 35 a 44 años & $17.9 \%$ & $19.3 \%$ \\
\hline 45 a 54 años & $14.3 \%$ & $10.7 \%$ \\
\hline 55 a 64 años & $11.5 \%$ & $3.2 \%$ \\
\hline & & \\
\hline
\end{tabular}

Fuente: Marco General de los Medios en España. AIMC.2004

\footnotetext{
2 En el informe de 2004 de la Fundación Auna, España ocupa el $17^{\circ}$ lugar en la Europa de los 25 en términos de desarrollo global de la sociedad de la información. Otros indicadores confirman el relativo retraso tecnológico de España: para el E-Readiness Index está en el puesto $21^{\circ}$, para el Information Society Index en el $25^{\circ}$ y para el Network Readiness Index en el $29^{\circ}$
} 
Los servicios más utilizados en el último mes por la población en general han sido con gran diferencia la navegación por las webs $(92 . \%)$ y el correo electrónico (82.1\%), y a una distancia importante la transferencia de ficheros $(29.3 \%)$ y el uso de los chats $(25.6 \%)$. Aunque existen programas para controlar contenidos no adecuados para los niños ${ }^{3}$ (http://www.internetsegura.net), no deja de ser inquietante que, según un estudio del órgano de la Comisión Europea, Investigación Europea de Asuntos de los Consumidores (ERICA), dentro del programa 'Internet más segura', del medio centenar de sitios web infantiles con más tráfico (en alemán, inglés, francés, italiano, español, holandés y catalán), la cuarta parte incluye material que el Ejecutivo comunitario considera inadecuado para los niños tales como juegos e imágenes violentas, juegos de azar, apuestas, chistes sexistas, información sobre artes marciales y enlaces a agencias de contactos. Por otra parte, desde hace algún tiempo se observa en Internet la proliferación de webs que hacen la apología de la anorexia (pro-ana) y la bulimia (pro-mia), que deterioran gravemente las conductas alimentarias, y promueven dietas y trucos para perder peso y que entrañan serios problemas para la salud, especialmente de las jóvenes adolescentes. Son webs de carácter general, por lo que no están tipificadas como delictivas, aunque esas secciones supongan un serio problema para pacientes con dichos problemas.

Tabla 11. Tiempo diario que los niños y jóvenes británicos dedican a Internet (2004)

\begin{tabular}{|c|c|}
\hline porcentaje & fiempo de uso diario \\
\hline $19 \%$ & 10 minutos \\
\hline $25 \%$ & 30 minutos \\
\hline $23 \%$ & 60 minutos \\
\hline $14 \%$ & de 1 a 2 hora \\
\hline $6 \%$ & de 2 a 3 horas \\
\hline $5 \%$ & más de 3 horas \\
\hline
\end{tabular}

Fuente: elaboración propia con datos de UK Children go on online

\footnotetext{
3 La Fundació Catalana per la Recerca creó el programa INTERNET SEGURA, el año 2000 en Cataluña. Para hacer frente a la creciente demanda de información y recursos, el programa implementó a partir de enero del 2001 un nuevo proyecto europeo de sensibilización, Dot.Safe, para crear materiales específicos para las escuelas. A partir de enero del 2002, el programa se añadió a dos proyectos más, uno de prevención, el POESIA (con el objetivo de crear un software libre que filtrase contenidos ilegales y nocivos de Internet) y el proyecto Euncle (para crear una herramienta colaborativa, multilingüe, para niños y niñas). A finales del año 2002, la Fundació Catalana per

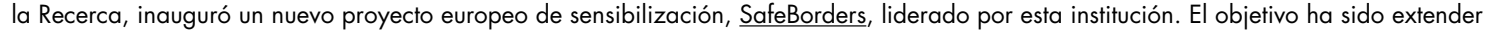
el programa INTERNET SEGURA en toda España y a otros 6 países europeos (ltalia, Gran Bretaña, Alemania, Grecia, Paises Bajos y Luxemburgo), contribuyendo así a la creación de una gran red europea que promueva la seguridad de los menores en Internet.
} 
Carmelo Garítanandia Emilio Fernández Jose Antonio Oleaga,

Tabla 12. Principales usos de Internet por los niños y jóvenes británicos (2004)

\begin{tabular}{|c|l|}
\hline porcentaje & \multicolumn{1}{|c|}{ Uso } \\
\hline $90 \%$ & para trabajos de escuela, instituto y Universidad \\
\hline $94 \%$ & para obtener información para otras cosas \\
\hline $72 \%$ & para enviar y recibir mensajes \\
\hline $55 \%$ & para enviar y recibir mensajes instantáneos \\
\hline $45 \%$ & para descargar música \\
\hline $21 \%$ & uso de chats \\
\hline
\end{tabular}

Fuente: elaboración propia con datos de 'UK Children go on online'

Quizá uno de los problemas más importantes de los niños y jóvenes con Internet es la facilidad que tienen para encontrar sexo y pornografía en la red. No sólo en las web en general, sino a veces en las específicas infantiles. De hecho, según el estudio británico "UK children go online" realizado en los primeros meses del 2004, más de la mitad de los niños y jóvenes británicos han tenido contacto con pornografía online al menos una vez a la semana. Aunque todavía no es el caso español, lo podría ser en breve.

Tabla 13. Contacto de los niños y jóvenes británicos con la pornografía en Internet (2004)

\begin{tabular}{|c|l|}
\hline porcentaje & \multicolumn{2}{|c|}{ tipo de confacto } \\
\hline $57 \%$ & $\begin{array}{l}\text { navegando han tenido al menos una vez a la semana contacto con } \\
\text { pornografía online }\end{array}$ \\
\hline $38 \%$ & $\begin{array}{l}\text { han visto una pop-up pornográfica mientras hacían otra cosa } \\
\text { han encontrado accidentalmente una web pornográfica cuando buscaban } \\
\text { otra cosa }\end{array}$ \\
\hline $25 \%$ & $\begin{array}{l}\text { han recibido correo (spam) pornográfico por e-mail o mensajería } \\
\text { instantánea }\end{array}$ \\
\hline $10 \%$ & han visitado a propósito una web pornográfica \\
\hline $9 \%$ & le ha enviado pornografía alguien que conoce \\
\hline $2 \%$ & le ha enviado pornografía alguien que ha conocido en la red \\
\hline
\end{tabular}

Fuente: elaboración propia con datos de 'UK Children go on online'

Si dejamos al margen la natural curiosidad sexual que motiva esa búsqueda, y que no tiene en general mayores consecuencias, el problema reside en cómo esa facilidad para encontrar páginas sexuales de diferente índole va a influir en el comportamiento futuro de los niños y los jóvenes.

\section{LA PEQUEÑA REVOLUCIÓN SILENCIOSA DEL TELÉFONO MÓVIL}

Posiblemente ninguna tecnología en la historia ha tenido un grado de penetración tan rápido y tan extenso entre los jóvenes como ha sido el teléfono móvil, y ninguna ha influido tan aceleradamen- 
te en sus vidas. La gran mayoría de los jóvenes españoles ${ }^{4}$ tiene teléfono móvil (89.2\%) (Valor y Sieber, 2003), además su uso no tiene relación con el grado de conocimientos tecnológicos de los jóvenes, como puede suceder con el ordenador. Este nivel de equipamiento es bastante similar al de países de nuestro entorno, si bien en algunos de ellos, como ltalia, el éxito de la revolución del móvil se extiende a las más cortas edades. Así uno de cada dos niños italianos de entre siete y once años tiene un teléfono celular. Entre los factores de éxito de esta revolución tecnológica está el que el teléfono móvil contribuye a la socialización de los menores, ya que reduce la soledad y la ansiedad, a la vez que aumenta el sentido de la seguridad de los propios menores, pero, sobretodo, de los padres. Sirva como ejemplo esta declaración de Marikay Termini cuya hija lleva el móvil al instituto: "The cellphone is not for her convenience. It's for her security. It's for my peace of mind." (New YorkTimes, 29-09-04). Este uso de la tecnología móvil permite mantener la cohesión entre los miembros de la familia (muchas veces son los padres los que llaman a sus hijos para saber donde están). El $64.7 \%$ de los jóvenes españoles llaman a sus amigos varias veces al día, o casi todos los días, y a sus padres en el $42.3 \%$ de los casos con la misma frecuencia (Valor y Sieber, 2003).

Frente a esta visión de cohesión familiar, existe otra virtualidad del uso de los teléfonos móviles que no es otra que la conquista de la privacidad por parte de los adolescentes. Esta vertiente adquiere especial relevancia en la utilización del móvil en Japón, país avanzadilla de los nuevos servicios multimedia a través del móvil y con un uso muy intensivo por parte de los jóvenes. En Japón los teléfonos móviles "han desencadenado un cambio de poder intergeneracional porque han iberado a los jóvenes de la tiranía de la telefonía por cable compartida por los familiares más inquisitivos, de manera que se ha creado un espacio para la comunicación privada y una instancia que amplía las posibilidades de acción social" (Rheingold, 2004:32). Para este autor los mensajes cortos de textos son un instrumento ideal de intimidad y relación social entre los jóvenes que les permite comunicarse con los miembros de su grupo de amigos (de 3 a 5 personas) sin el control de los padres. (Rheingold, 2004:33)

Prácticamente las desventajas del uso de los móviles por niños y jóvenes se reducen a dos. La primera es que el lenguaje sintético que usan en los mensajes de texto, y un tanto críptico para los adultos, tiende a empobrecer su lenguaje, sobre todo entre los más pequeños que no lo han adquirido todavía con total competencia, por lo que algunos especialistas desaconsejan los móviles para menores de 14 años. La segunda es de orden médico. Algunos especialistas, entre ellos el catedrático de biología William Steward que hizo el informe sobre "móviles y salud" que lleva su nombre para el Departamento de Salud del Gobierno Británico, desaconseja el uso excesivo de móviles a los menores de 16 años, ya que si la exposición a ondas electromagnéticas provoca efectos nocivos para la salud, éstos serían más negativos en los jóvenes, dado que sus cráneos son más delgados y absorben más fácilmente las radiaciones (Steward, 2000).

\footnotetext{
4 La muestra del sondeo se hizo a través de Internet y presencial, en el último trimestre de 2002, y se obtuvieron más de 1.200 respuestas válidas. En la encuesta se analizaban cuatro diferencias: sexo, nivel de conocimientos tecnológicos, lugar de residencia y edad, entre adolescentes (14 a 17 años) y los adultos jóvenes (18 a 22 años).
} 
Aunque evidentemente el uso de los móviles tiene también un componente lúdico, incluso de juego en los móviles de última generación, prima el componente comunicativo como lo demuestra el hecho de que los mensajes, las llamadas y la localización del usuario por amigos y/o familiares sean los aspectos más valorados. En torno al $63 \%$ de los jóvenes envían varios mensajes al día, y $27 \%$ casi todos los días. Las chicas utilizan más el SMS que los chicos. Y en general, los jóvenes que hacen más llamadas son los que más usan el SMS. Además de las llamadas y de los mensajes, el móvil cumple una función de agenda, muy importante, prácticamente todos han desechado el papel, y sin embargo otras funciones posibles (y que quizá a medio plazo puedan tener un gran éxito con la tecnología UMTS) como los juegos, el correo electrónico, la recepción de noticias y la navegación por Internet con el móvil tienen todavía un uso muy restringido.

\section{ALGUNAS CONCLUSIONES}

Los niños y los jóvenes actuales parecen haber integrado perfectamente en sus vidas todos los aparatos multimedia que les permiten el acceso al ocio, la comunicación, la información y el conocimiento. Muestran una relación perfectamente normal con las nuevas y viejas tecnologías de la información y su grado de asunción de las mismas, junto con su corta perspectiva vital, les lleva a no diferenciar entre viejas y nuevas tecnologías como hacen los adultos. Existe una estrecha relación de cotidianidad entre los jóvenes y esos aparatos multimedia que permiten el acceso al ocio, la comunicación y la información. La relación de cotidianidad que mantienen con estos dispositivos hace que ninguno declare tener mala relación o alguna prevención, ni que parezcan tener una relación patológica con ellos. Evidentemente ésta es una relación bien diferente a la que han tenido y tienen sus padres y sus abuelos con las tecnologías de la información y la comunicación. La asunción por parte de los padres y los abuelos de estas tecnologías en diferentes etapas de su vida conduce a un distinto grado de integración de las mismas, dependiendo de la etapa de sus vidas en las que han llegado y del nivel de formación general y de alfabetización digital de estos adultos.

Los niños y los jóvenes consideran sólo la versión lúdica de los aparatos que manejan con más asiduidad (televisión, vídeo/dvd, ordenador, consola, juegos electrónicos, walkman, cadena de sonido, radio). Aunque el factor de diversión es importante también en los teléfonos móviles, en su uso prima el factor comunicación, como lo demuestra el hecho de que los mensajes, las llamadas y la localización sean los aspectos más valorados y con mucha diferencia respecto a otros. Los mayores encuentran también un uso escolar al ordenador/Internet, pero incluso éstos sólo usan estos aparatos tecnológicos para jugar o distraerse. Así, en el ordenador, la consola y los juegos electrónicos destaca su rol de juego; el vídeo, la televisión, la radio, el walkman y la cadena de sonido tienen un rol de entretenimiento; en ninguno de ellos prepondera su aplicación cultural; y sólo el ordenador/Internet para los mayores mantiene cierta asociación con un rol de trabajo. Ese componente lúdico asociado a los equipamientos tecnológicos es el que permite que los jóvenes vean estos aparatos como medio de comunicación en tres sentidos: 
Primero, el mero hecho de usarlo en compañía de amigos, hermanos, padres o parientes hace, desde su punto de vista, que tengan que relacionarse con ellos, aprendiendo a comportarse durante el juego, interactuando con los demás, es decir, aprendiendo a asumir los papeles de interaccion social que les servirán para su desempeño como adultos.

Segundo, estas tecnologías y el software que las acompaña tienen una función de cohesión social, establecen lazos de acercamiento entre los jóvenes y les permite tener sentimientos de pertenencia a un grupo. Estos aparatos y sus funciones lúdicas son también tema de conversación entre los jóvenes, que tanto pueden hablar del soporte en sí (consola "Nintendo 64", el último modelo de ordenador) como de los distintos juegos. Es fácil ver a jóvenes de las edades estudiadas hablar con vehemencia de los distintos tipos de juegos, las ventajas de uno y las desventajas de otro, de los juegos que les han regalado recientemente, de los juegos que van a pedir en navidades (los menores) o de los nuevos juegos de Internet o de las salas de máquinas (los mayores).

Tercero, la escasez de medios económicos de muchos niños y jóvenes hace que tengan que cambiarse los juegos, que los pirateen (sobre todo los mayores), que los descarguen de la red, que se regalen o intercambien entre sí los juegos de ordenador o los videojuegos.

Para los niños y para los jóvenes, en su conjunto, estos aparatos permiten comunicarse con los demás, tanto con sus padres (a través de los propios juegos, el uso y las instrucciones o a través de sus peticiones de compra de juegos) como con los componentes del grupo de amigos. El móvil, por ejemplo, ha favorecido la comunicación de los niños y jóvenes con sus iguales y con sus padres.

No parece que el uso de estos aparatos, incluido el uso de Internet (probablemente el abuso), cree ningún tipo de problemas en las relaciones de los niños y de los jóvenes con sus padres (y familia), con sus amigos y con sus profesores. No tenemos ningún indicio que nos haga pensar que estos aparatos repercuten en estas relaciones deteriorándolas.

Los niños y los jóvenes son un grupo de edad de gran valor estratégico para los productores de contenidos y servicios multimedia del mañana. Sus actuales modos de acceder a los contenidos y de comunicarse con sus homólogos marcará cómo serán los servicios del futuro en la televisión digital, en Internet o en el medio preponderante los próximos años. Las grandes empresas de contenidos multimedia saben que los jóvenes quieren interactuar con unos medios rápidos y fáciles en el acceso y que nada tiene sentido en su consumo si no puede ser compartido con sus amigos (Griffiths, 2003:24).

A medida que los niños se hacen adolescentes van ganando peso sus propios amigos. Y es importante observar e insistir en que los jóvenes siguen teniendo claro, a pesar de la presencia masiva de equipamientos tecnológicos en sus vidas, que los amigos tienen un papel estelar frente a los aparatos. A pesar del apego a ciertos aparatos que tienen los niños y los jóvenes, todos siguen prefiriendo y poniendo en primer lugar a los amigos antes que a las máquinas. 
Carmelo Garitaonandia Emilio Fernández Jose Antonio Oleaga.

\section{REFERENCIAS BIBLIOGRÁFICAS}

=Alonso M.; Matilla L.; Vázquez M., (1995): "Teleniños públicos. Teleniños privados" Madrid: Ediciones de la Torre .

-Asociación para la Investigación en Medios de Comunicación, AIMC/EGM (2003): Audiencia infantil/ Juvenil de Medios en España, AIMC, Madrid, (http://www.aimc.es).

- Asociación para la Investigación en Medios de Comunicación, AIMC/EGM (2003): Navegantes en la red: sexta encuesta, Madrid, (http://www.aimc.es).

- Beentjes, J.W., Koolstra, CM and Van der Voort, T.H.A. (1996): "Combining back-ground media with doing homework: incidence of background media use and perceived effects", Communication Education , 45 (1), Enero, pp. $59-72$.

- Berrou, L. (1994): Les méfaits de la television sur nos enfants, Paris: Ed. Avenir de la Culture.

- Chou, Chien (2000): "Internet addiction, usage, gratification, and pleasure experience: the Taiwan college students' case". Computers and Communication, Vol. 31, n 1. pp. 65-80

- Dubow E and Miller L.S. (1996): "Television violence viewing and aggressive behavior", pp. 117-147, en Macbeth T.M. Ed. Tuning in to young viewers, California: Sage Publications.

= Everett S. L. (1994): "The endangered post-modern childhood", INTERMEDIA N²2, pags 30-33.

- Fisher, S. (1994) "Identifying video game addiction in children and adolescents" Addictive Behaviors 19(5): pp. 545-553.

- García Calera, M.C. (2000): "Televisión, violencia e infancia. El impacto de los medios", Barcelona: Gedisa.

- García Muñoz, N. (1997): "Los hábitos del niño frente al televisor en el hogar", en ZER, N³, pp. 67-81 (http://www.ehu.es/zer).

- Garitaonandía, C., Juaristi, P. y Oleaga, J.A. (1999): "Qué ven y cómo juegan los niños y los jóvenes españoles", ZER, No6, pp. 67-97 (http://www.ehu.es/zer).

- Garitaonandía, C., Juaristi, P. y Oleaga, J.A., (1998): "Las relaciones de los niños y los jóvenes con las viejas y las nuevas tecnologías de la Información", ZER, N4, pp. 131-161 (http://www.ehu.es/zer).

- Griffiths, A. (2003): Digital Television Strategies: Business Challenges and Opportunities: New York: Palgrave MacMillan.

- Himmelweit, Hilde T. (1958), Television and the child, Londres: Ed. Nuffield Foundation.

- Houston A.C. \& Wright J.C. (1996): "Television and socialization in young children", pp. 37-60, en Macbeth T.M. Ed. Tuning in to young viewers, California: Sage Publications.

- Kline, S. (1993): Out of the garden: toys, TV and children's culture in the age of marketing, Londres y New York: Garamond Press.

- Koolstra, CM. and Van der Voort, T.H.A. (1996): "Longitidinal effects of television on children's leisure time-reading: a test of three explanatory modesl", Human Communication Research, 23 (1), Sept. 1996.

- Koolstra, CM. and Van der Voort, T.H.A. (1997): "Televisions's impact on children's reading comprehension and decoding skills: a 3-year panel study", Reading Research Quarterly 32 (2), Abril-Junio 1997. 
- Kubey, R.W. (1996): "Television dependence, diagnosis and prevention: with commentary on video games, pornography, and media education", pp. 221-260, en Macbeth T.M. Ed. Tuning in to young viewers, California: Sage Publications.

- Ledingham, Jane E. (1993): The effects of media violence on children: a background paper, Canada: The Clearinghouse.

- Livingstone, S., Bober, M. (2004): "UK children go online", Economic \& Social Research Council, London, July (http://www.children-go-online.net).

- Livingstone, S., Bovill, M. Editors, (2001): "Children and their Changing Media Environment. A European Comparative Study", Mahwah (New Jersey) and London: Lawrence Erlbaum Associates Publishers.

- Matute, H. (2003): "Adaptarse a Internet. Mitos y realidades sobre los aspectos psicológicos de la red", La Coruña: La Voz de Galicia.

- Muñoz, J.J., Pedrero, L.M. (1996): La televisión y los niños, Salamanca: Ed. Librería Cervantes.

- Neuman, S.B. (1991): Literacy in the television age: the myth of the TV effect, Estadops Unidos: Abblex.

- New York Times, 29-9-2004.

- Nikken P., Van der Voort T.H.A., \& Van Bochove E (1996): "Maternal quality standards for children's television programs", Journal of Educational Media 22 (1), Primavera 1996, pp. $41-54$.

- Pérez Ornia, J.R., Nuñez Ladevéze, L. (2003): "La programación televisiva infantil en España", TELOS n54, enero-marzo, páginas 103-114 (http://www.campusred.net/telos).

- Perez Tornero J. M. (1994): El desafio educativo de la televisión. Para comprender y usar el medio, Barcelona: Ed. Paidós.

- Potten W.J., Warren R. (1996): "Considering policies to protect children from TV violence", Journal of Communications , 46(4), pp. $116-138$

- Pratarelli, M \& Browne, B (2002): "Confirmatory Factor Analysis of Internet Use and Addiction", CyberPsychology and Behavior, Vol 5, n 1. pp. 53-64

- Prieto Barrero M. [et al.] (1994): Televisión, niños y jóvenes, Valencia: Ed. por Radiotelevisión Valenciana.

- Rheingold, H. (2004): Multitudes Inteligentes: La Próxima Revolución Social (Smart Mobs), Barcelona: Gedisa Editorial.

- Rico, L. (1992): TV Fábrica de mentiras: la manipulación de nuestros hijos, Madrid: Ed. Espasa Calpe.

noberts, D.F., Foehr, U.G. (2004) "Kids and Media in America", Cambridge University Press.

- Sartori, Giovanni (1998). Homo Videns: La Sociedad Teledirigida, Madrid: Taurus.

- Sefton-Green, J., Buckingham, D. (1996): "Digital visions's "creative" uses of multimedia technologies", Convergence , 2(2), Otoño 1996.

- Sherman, S. (1996): "A st of one's own: TV sets in children's bedrooms", Journal of Advertising Research 36(6), Noviembre -Diciembre, RC9-RC12. 
- Signorielli N. (1991):A sourcebook on children and television, Nueva York: Ed.Greenwood Press.

- Steward, W. (2000): Mobile Phones and Health. Independent Expert Group in Mobile Phones. Consultado en http://www.iegmp.org.uk/documents/cover.pdf el 11 de diciembre de 2004

- Valor, J., Sieber, S. (2003), "Uso y actitud de los jóvenes ante Internet y la Telefonía móvil", en <http://www.iese.edu/es/files/5_9073.pdf consultado el 4 de diciembre de 2004

- Wartella, E. ed. (1996): National Violence study, volume 1, Thousand Oaks, California: Ed. Sage Publications

- Wartella, E. ed. (1997): National Violence study, volume 2, Thousand Oaks, California. 